\title{
Fate of nonylphenol polyethoxylates and their metabolites in four Beijing wastewater treatment plants
}

\author{
J. Lian, J.X. Liu* ${ }^{*}$ Y.S. Wei \\ Research Center for Eco-Environmental Sciences, Chinese Academy of Sciences, Beijing 100085, PR China
}

\section{A R T I C L E I N F O}

\section{Article history:}

Received 18 December 2008

Received in revised form 18 March 2009

Accepted 22 March 2009

Available online 22 April 2009

\section{Keywords:}

Nonylphenol polyethoxylates

Metabolites

Wastewater treatment plant

Fate

Pathways

\begin{abstract}
A B S T R A C T
Four Beijing wastewater treatment plants (WWTPs) were selected to investigate behaviours of nonylphenol polyethoxylates and their metabolites in different wastewater treatment processes. The results showed that the total concentrations of nonylphenolic compounds in the influents of the four WWTPs ranged from 0.115 to $0.347 \mu \mathrm{mol} / \mathrm{L}$, as well as their removal efficiencies ranging from $75.7 \%$ to $90.8 \%$. Both influent concentrations and removal efficiencies of nonylphenol polyethoxylates were correlated to seasons as follows: higher in the summer than in the winter, and influent concentrations were lower during the rain weather. The analysis revealed that $21.8-47.6 \%$ of nonylphenol polyethoxylates and their metabolites entering WWTPs were released via effluents and excess sludge, leaving a great part of them for biodegradation. Nonylphenol and short-chain nonylphenol polyethoxylates were disposed to the environment mainly via sewage sludge, while carboxylated nonylphenol polyethoxylates were the most abundant group of nonylphenol polyethoxylates in effluents.
\end{abstract}

(c) 2009 Elsevier B.V. All rights reserved.

\section{Introduction}

Nonylphenol polyethoxylates (NPnEOs, $n$ : number of ethoxy units) are an important group of non-ionic surfactants, which are manufactured and utilized in many households, institutions and industries. The worldwide production of alkylphenol ethoxylates (APEOs) has been estimated to be 500,000 tons per year (Fujita and Reinhard, 1997), of which NPnEOs account for approximately $80 \%$. Since 1995, the consumption of NPnEOs in China has increased steadily, and its estimated total consumption is 60,000 tons per year in recent years (Zhang et al., 2007). Previous literatures have suggested that NPnEOs consist in municipal wastewater. Throughout the wastewater treatment, due to biodegradation, NPnEOs undergo a rapid transformation into short-chain NPEOs such as nonylphenol monoethoxylate (NP1EO) and nonylphenol diethoxylate (NP2EO), nonylphenol (NP), and carboxylated derivatives including carboxylated NPnEOs (NPECs) and dicarboxylated NPnEOs (CAPECs) (Soares et al., 2008). NP and short-chain NPnEOs $(n=1.2)$ are lipophilic compared with the long-chain ethoxylates, and have been reported to cause a number of estrogenic responses on aquatic organisms, thus they have been classified as endocrine disruptors (EDCs) (Scrimshaw and Lester, 2003). Moreover, NP1EC and NP2EC are also proved to have the estrogenic properties (Harries et al., 1996). Therefore, the exposure of these persistent and toxic biodegradation products with the release of effluent and excess sludge during wastewater treatment plants (WWTPs) has been paid more and more attention.

\footnotetext{
* Corresponding author. Tel./fax: +86 1062849133.

E-mail address: jxliu@rcees.ac.cn (J.X. Liu).
}

So far, the fate and occurrence of NPnEOs and their metabolites in WWTPs have been well documented through several studies around the world (Jobling and Sumpter, 1993; Korner et al., 2000; Soares et al., 2008; Stasinakis et al., 2008). However, most of the reports limited the number of analytes to NP and NPnEOs, while only a few reports included NPECs and CAPECs (Ahel et al., 1994; Corcia et al., 2000; Fujita et al., 2000; Loyo-Rosales et al., 2007). Especially in China, there has been no data for NPECs in WWTPs up to date. Moreover, despite the existence of several studies investigating the presence of nonylphenolic compounds in WWTPs, most of them focused exclusively on concentrations in influents and effluents (Ma et al., 2002; Shao et al., 2003; Наo, 2007), and then removal efficiencies were obtained. Only a few reports have made mass balance of nonylphenolic compounds in WWTPs to obtain the output pathways of nonylphenolic compounds (Ahel et al., 1994; Bruno et al., 2002; Loyo-Rosales et al., 2007). Moreover, the contributions of the pathways were rarely determined probably due to the difficulty in detecting all the nonylphenolic compounds in wastewater and sludge samples and in getting accurate operational parameters of WWTPs. In addition, the fate of organic compounds during wastewater treatment processes is controlled by physical, chemical and biological processes of wastewater treatment (Scrimshaw and Lester, 2003). NP, short-chain NPnEOs, long-chain NPnEOs and NPECs may display different output modes because of their different physical and chemical properties. However, much less reports are available for the output pathway of each kind of NPnEOs metabolites.

In this study, a comprehensive study on the occurrence, transformation and elimination of NPnEOs and their metabolites was carried out in four full-scale WWTPs of Beijng, China. The impacts of weather on the behaviour of NPnEOs and related compounds were also investigated. 
These results would be helpful to assess and control removal of NPnEOs and their metabolites, in order to improve the work efficacy of WWTPs in China.

\section{Materials and methods}

\subsection{Standard solutions and reagents}

4-NP (technical grade), a mixture of compounds with branched side chains, was obtained from TCI Chemicals (Tokyo, Japan). Pure NP1EO, pure NP2EO and NPECs mixture standards (with EO chain lengths from 0 to 9, corresponding from NP1EC to NP10EC) were purchased from Hayashi Pure Chemicals (Osaka, Japan). A non-ionic surfactant, Igepal CO630 (a commercial nonylphenol polyethoxylate mixture with an average of 9EO units), was obtained from Sigma-Aldrich (Gillingham, UK). Standard stock solutions were prepared in methanol. Sodium acetate (p.a) was purchased from Beijing Chemical Reagents Company. Dichloromethane, methanol and hexane were HPLC grade (Fisher Chemical Co., USA). Ultra pure water was prepared using a CUPW-10N ultrapure water system (Liyuan, China) at a conductivity of $18.3 \Omega \cdot \mathrm{cm}^{-1}$. Silica-based bonded C18 (Sep-Pak, 6 cc, $500 \mathrm{mg}$ ) and poly (divinylbenzene-co- $N$-vinylpyrrolidone) (Oasis HLB, $6 \mathrm{cc}, 500 \mathrm{mg}$ ) cartridges were supplied by Waters (Milford, MA, USA).

\subsection{WWTPs surveyed and sampling}

Four full-scale WWTPs in Beijing were studied from June to December in 2007 and July in 2008. Information on the individual plant and their operational parameters are summarized in Table 1. Plant 1 , plant 2 and plant 4 receive both industrial and domestic wastewaters, while plant 3 treats only domestic wastewater. The treatment processes of the four WWTPs are different from each other, being anaerobicanoxic-oxic $\left(\mathrm{A}^{2} \mathrm{O}\right)$, anaerobic-oxic $(\mathrm{AO})$, anaerobic-anoxic-oxic $\left(\mathrm{A}^{2} \mathrm{O}\right)$ combined with biofilm and oxidation ditches, respectively. Twentyfour-hour composite samples of influents were taken in each of WWTPs, while grab effluents samples and sludge samples were collected from each processing unit of the WWTPs. All sampling campaigns were conducted during the dry weather, except for two sampling events in the rain weather, on July 11 th and 14th in 2008, respectively. Wastewater and sewage sludge samples were collected in pre-cleaned amber glass bottles. Soon after the sampling, wastewater samples were added with formaldehyde $(1 \%, \mathrm{v} / \mathrm{v})$, then filtered and stored in the dark at $4{ }^{\circ} \mathrm{C}$. The filters were air-dried and weighed to calculate suspended solids, and extracted to evaluate NPnEOs and relative compounds. Their extraction was performed within $48 \mathrm{~h}$ of their arrival. Sludge samples were frozen at $-20{ }^{\circ} \mathrm{C}$ before freeze-dried (ALPHA 1-2LD PLUS, Christ, Germany). After lyophilization, the sludge was homogenized and stored frozen, wrapped in aluminum foil, to avoid any contact with plastic material.

\subsection{Extraction and analysis}

For wastewater, a volume of $500 \mathrm{ml}$ of wastewater sample was filtered through a pre-ashed $\left(4 \mathrm{~h}, 450^{\circ} \mathrm{C}\right)$ glass fiber filter $(\mathrm{GF} / \mathrm{F}$, pore size $0.7 \mu \mathrm{m}$, Whatman, Brentford, Middlesex, UK) and acidified with concentrated $\mathrm{HCl}$ (37\%, GR). A HLB cartridge was conditioned

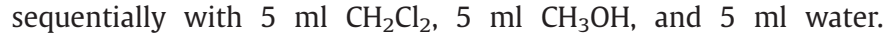
The acidified water $(\mathrm{pH}=3)$ was passed through the HLB cartridges at $5-10 \mathrm{ml} / \mathrm{min}$, and the residual water was removed by passing a gentle nitrogen stream through the cartridges for about $30 \mathrm{~min}$. A total of $10 \mathrm{ml}$ of $\mathrm{CH}_{2} \mathrm{Cl}_{2} / \mathrm{CH}_{3} \mathrm{OH}$ (80:20, v/v) was used as eluent, and passed through the sorbent beds at a rate of $2 \mathrm{ml} / \mathrm{min}$ to desorb NPEOs. The eluent was dried under a gentle nitrogen stream followed by adding $0.05 \mathrm{ml} \mathrm{4}$-n-NP (10 mg/L in hexane) and $100 \mu \mathrm{L}$ BSTFA + TMCS reagents, then reconstituted with $1 \mathrm{ml}$ hexane, $0.4 \mathrm{ml}$ of which was separated to analyze NP and NPnEOs $(n=1,2)$ with gas chromatograph-mass spectrometer (GC-MS). For the quantitative analysis, a gas chromatograph 6890 Series connected to a MSD 5975i was used (Agilent. USA). The carrier gas was helium and maintained at a constant flow rate of $0.9 \mathrm{ml} \cdot \mathrm{min}^{-1}$. A sample volume of $1 \mu \mathrm{L}$ was injected in splitless mode at an inlet temperature of $300{ }^{\circ} \mathrm{C}$. The column temperature was programmed as follows: at $50{ }^{\circ} \mathrm{C}$ for $1 \mathrm{~min}$, from $50{ }^{\circ} \mathrm{C}$ to $200{ }^{\circ} \mathrm{C}$ at a rate of $20{ }^{\circ} \mathrm{C} / \mathrm{min}$, at $200{ }^{\circ} \mathrm{C}$ for $2 \mathrm{~min}$, from $200{ }^{\circ} \mathrm{C}$ to $235^{\circ} \mathrm{C}$ at a rate of $5^{\circ} \mathrm{C} / \mathrm{min}$, at $235^{\circ} \mathrm{C}$ for $5 \mathrm{~min}$, from $235^{\circ} \mathrm{C}$ to $280{ }^{\circ} \mathrm{C}$ at a rate of $25{ }^{\circ} \mathrm{C} / \mathrm{min}$, and at $280{ }^{\circ} \mathrm{C}$ for $5 \mathrm{~min}$. The EI conditions were: ionization energy, $70 \mathrm{eV}$; electron multiplier voltage, $1.45 \mathrm{kV}$. Quantitative analysis was carried out using selected ion monitoring (SIM) mode. For each compound, the most abundant ions were selected from its spectrum. The chosen ions for SIM were 179 for 4-n-NP; 221,179,193 for NP; 251,265 for NP1EO; and 295,309 for NP2EO. The remaining $0.6 \mathrm{ml}$ hexane was dried and reconstituted with $1 \mathrm{ml} \mathrm{CH} \mathrm{CH}_{3} \mathrm{OH} /$ water $(1: 1, \mathrm{v} / \mathrm{v})$ for liquid chromatographyelectrospray ionization-mass spectrometry (LC-ESI-MS) analysis, in order to detect NPnEOs $(n \geq 3)$ and NPECs (Zhang et al., 2007). Analysis were performed on an Alliance 2690 HPLC (Waters Corporation, USA) equipped with a C18 analytical column $(2.1 \mathrm{~mm}$ in ID $\times 150 \mathrm{~mm}$ in length, $3 \mu \mathrm{m}$ Waters Symmetry Shield, USA) and ZQ4000 MSD (Waters Corporation, USA). The column oven was at $40{ }^{\circ} \mathrm{C}$, and the injection volume was $20 \mu \mathrm{L}$. The mobile phases consisted of water containing $0.1 \mathrm{mmol} / \mathrm{L}$ sodium acetate $(\mathrm{A})$ and methanol (B). The flow was kept at $0.2 \mathrm{ml} / \mathrm{min}$ for $5 \mathrm{~min}$ with $30 \%$ methanol, then the methanol was linearly increased to $85 \%$ in $7 \mathrm{~min}$ and held for 9 min, afterwards changed to $97 \%$ immediately and held for $6 \mathrm{~min}$, finally brought back to 30\% and held for $7 \mathrm{~min}$ to the next injection. The capillary voltage was $3.5 \mathrm{kV}$; the cone voltage was $30 \mathrm{~V}$; source temperature and desolvation gas temperature were set to $100{ }^{\circ} \mathrm{C}$ and $300{ }^{\circ} \mathrm{C}$; the flow rate of the desolvation gas and cone gas were $250 \mathrm{~L} / \mathrm{h}$ and $60 \mathrm{~L} / \mathrm{h}$ respectively. The full scan mass ranged from 200 to 1500 Da with a scan time of $1 \mathrm{~s}$.

For sludge samples and solids on the filter membranes, target compounds were extracted with a solvent mixture of $\mathrm{CH}_{2} \mathrm{Cl}_{2} / \mathrm{CH}_{3} \mathrm{OH}$ (70:30, v/v). One gram of lyophilized and homogenized sludge sample or a piece of lyophilized filter membrane with solids on it was sonicated for $10 \mathrm{~min}$ with $15 \mathrm{ml}$ of the solvent mixture. The extract was separated by centrifugation at $4000 \mathrm{rpm}$ for $10 \mathrm{~min}$, and the procedure was repeated three times. The extracts were combined, concentrated to an approximate volume of $1 \mathrm{ml}$ using a rotary vacuum evaporator at $35^{\circ} \mathrm{C}$, and redissolved in $500 \mathrm{ml}$ of water. Subsequent cleanup of extracts was performed by SPE as described above, except

Table 1

Wastewater treatment plant characteristics and sampling events.

\begin{tabular}{|c|c|c|c|c|}
\hline & Plant 1 & Plant 2 & Plant 3 & Plant 4 \\
\hline Location in Beijing & North-west, $40^{\circ} 02^{\prime} \mathrm{N}, 116^{\circ} 21^{\prime} \mathrm{E}$ & East, $39^{\circ} 53^{\prime} \mathrm{N}, 116^{\circ} 31^{\prime} \mathrm{E}$ & East-south, $39^{\circ} 51^{\prime} \mathrm{N}, 116^{\circ} 26^{\prime} \mathrm{E}$ & South, $39^{\circ} 43^{\prime} \mathrm{N}, 116^{\circ} 23^{\prime} \mathrm{E}$ \\
\hline Capacity $\left(\times 10^{3} \mathrm{~m}^{3} /\right.$ day $)$ & 450 & 750 & 40 & 54 \\
\hline Wastewater source & Domestic, industrial & Domestic, industrial & Domestic & Domestic, industrial \\
\hline Treatment process & $\mathrm{A}^{2} \mathrm{O}$ & $\mathrm{AO}$ & $\mathrm{A}^{2} \mathrm{O}$ combined with biofilm & Oxidation ditches \\
\hline Sludge treatment & Centrifugal dewatering & Anaerobic digestion & Dewatering by filter press & Centrifugal dewatering \\
\hline HRT, h & 15 & $6-9$ & 9.6 & 9 \\
\hline SRT, d & $12-15$ & 20 & 10 & 15 \\
\hline Sampling events & June 2007, July 2007, September 2007, July 2008 & September 2007, December 2007 & October 2007, December 2007 & October 2007, July 2008 \\
\hline
\end{tabular}


Table 2

Method detection limits (MDLs), mean recoveries and relative standard deviations (RSDs) of nonylphenolic compounds in wastewater and sludge samples, obtained using GC-MS and LC-ESI-MS analysis.

\begin{tabular}{|c|c|c|c|c|}
\hline & \multicolumn{2}{|c|}{ Wastewater samples } & \multicolumn{2}{|c|}{ Sludge samples } \\
\hline & $\overline{\mathrm{MDL}(\mathrm{ng} / \mathrm{L})}$ & $\begin{array}{l}\text { Recovery(\%) } \pm \\
\operatorname{RSD}(\%)\end{array}$ & $\overline{\operatorname{MDL}(\mu \mathrm{g} / \mathrm{kg})}$ & $\begin{array}{l}\text { Recovery(\%) } \pm \\
\operatorname{RSD}(\%)\end{array}$ \\
\hline NP & 2.5 & $87 \pm 5.5$ & 6.5 & $80 \pm 7.4$ \\
\hline NP1EO & 2.5 & $88 \pm 5.6$ & 7.5 & $85 \pm 8.6$ \\
\hline NP2EO & 3.0 & $83 \pm 3.2$ & 11.0 & $78 \pm 6.7$ \\
\hline NPEOs $(n=3-15)$ & 0.02 & $81 \pm 5.8$ & 0.07 & $79 \pm 5.6$ \\
\hline NPECS & 0.1 & $88 \pm 6.4$ & 0.3 & $78 \pm 4.6$ \\
\hline
\end{tabular}

that the HLB cartridge was changed to C18 cartridge. The method detection limits (MDLs) and the recoveries of the nonylphenolic compounds, as well as relative standard deviations (RSDs) obtained using the above analytical method were listed in Table 2.

\section{Results and discussion}

\subsection{NPnEOs and their metabolites in the influents and effluents of the WWTPS}

Results of the analyses of NPnEOs and their metabolites in wastewater samples taken from the four WWTPs in Beijing are summarized in Table 3.
Based on their characteristic behaviour during wastewater treatment, NPnEOs and their metabolites were divided into four groups: NP, NPnEOs $(n=1,2)$, NPnEOs $(n \geq 3)$ and NPECs. Each oligomer of NPnEOs from NP3EO to NP15EO and each oligomer of NPnECs from NP1EC to NP10EC were detected respectively, and the presented levels of NPnEOs $(n \geq 3)$ and NPECs in the study were the sums of the concentrations of these oligomers. It is clear that the total concentrations of nonylphenolic compounds (NP-c) in the dry weather is related to industrial and domestic wastewater content in the WWTPs influents, i. e., 0.115 to $0.183 \mu \mathrm{mol} / \mathrm{L}$ of NP-c in the WWTPs receiving both industrial and domestic wastewaters, and $0.347 \mu \mathrm{mol} / \mathrm{L}$ of NP-c in the WWTP receiving only domestic wastewater. The concentrations of nonylphenolic compounds detected in this study fell into the range reported in other literatures (Ma et al., 2002; Planas et al., 2002; Hou and Sun, 2006; Stasinakis et al., 2008), but were at low level compared to those observed in the European countries, such as Switzerland (2.42-4.05 $\mu \mathrm{mol} / \mathrm{L}$ ) (Ahel et al., 1994) and United States (425-894 $\mu \mathrm{g} / \mathrm{L}$ for NP0-16EO) (Loyo-Rosales et al., 2007), indicating that the contamination in Beijing seemed less heavy than abroad, probably due to less consumption of NPnEOs surfactants in Beijing.

The relative abundance of the four groups of different NPnEOs relative compounds in the sewage influents of the four WWTPs is presented in Fig. 1a. The contribution of each nonylphenolic compound group in a WWTP is the average of the results obtained during several sampling events. NPnEOs $(n \geq 3)$ contributed 5.3-31.7\% to the total in the influents, accordingly, the sum of NP, NPnEOs $(n=1,2)$ and NPECs contributed to

Table 3

Occurrence (dissolved + particulate matter) and elimination of NP-c in four WWTPs of Beijing, China (ND, not detected).

\begin{tabular}{|c|c|c|c|c|c|c|c|c|}
\hline \multirow[t]{2}{*}{ Sampling time } & \multirow[t]{2}{*}{$T\left({ }^{\circ} \mathrm{C}\right)$} & \multirow[t]{2}{*}{ Samples } & \multicolumn{6}{|c|}{ Concentration $(\mu \mathrm{mol} / \mathrm{L})$} \\
\hline & & & $\overline{\mathrm{NP}}$ & NPnEOs $(n=1,2)$ & NPEOs $(n \geq 3)$ & NPECS & Sum & Removal (\%) \\
\hline \multicolumn{9}{|l|}{$\overline{\text { Plant1 }}$} \\
\hline \multirow[t]{2}{*}{ June, 14th } & \multirow[t]{2}{*}{25.7} & Inf. & 0.029 & 0.067 & 0.009 & 0.021 & 0.126 & 88.0 \\
\hline & & Eff. & ND & 0.004 & 0.001 & 0.010 & 0.015 & \\
\hline \multirow[t]{2}{*}{ July, 8th } & \multirow[t]{2}{*}{23.8} & Inf. & 0.035 & 0.044 & 0.005 & 0.031 & 0.115 & 75.7 \\
\hline & & Eff. & 0.001 & 0.008 & 0.001 & 0.018 & 0.028 & \\
\hline \multirow[t]{2}{*}{ July, 24th } & \multirow[t]{2}{*}{25.3} & Inf. & 0.032 & 0.053 & 0.007 & 0.038 & 0.130 & 80.8 \\
\hline & & Eff. & 0.002 & 0.002 & 0.001 & 0.020 & 0.025 & \\
\hline \multirow[t]{2}{*}{ Sep, 11th } & \multirow[t]{2}{*}{22.9} & Inf. & 0.042 & 0.052 & 0.008 & 0.043 & 0.145 & 81.4 \\
\hline & & Eff. & 0.002 & 0.001 & 0.001 & 0.023 & 0.027 & \\
\hline \multirow[t]{2}{*}{ July, 11th } & \multirow[t]{2}{*}{20.5} & Inf. & 0.019 & 0.032 & 0.004 & 0.021 & 0.076 & 82.9 \\
\hline & & Eff. & 0.001 & 0.001 & 0.001 & 0.010 & 0.013 & \\
\hline \multirow[t]{2}{*}{ July, 14 th $^{\mathrm{a}}$} & \multirow[t]{2}{*}{24.1} & Inf. & 0.021 & 0.036 & 0.005 & 0.014 & 0.076 & 85.5 \\
\hline & & Eff. & 0.002 & 0.001 & 0.001 & 0.007 & 0.011 & \\
\hline \multirow[t]{2}{*}{ July, 18th } & \multirow[t]{2}{*}{25.3} & Inf. & 0.040 & 0.055 & 0.008 & 0.018 & 0.121 & 86.0 \\
\hline & & Eff. & 0.002 & 0.004 & 0.001 & 0.010 & 0.017 & \\
\hline \multirow{2}{*}{\multicolumn{2}{|c|}{ Average \pm S.D. (in dry weather) }} & Inf. & $0.036 \pm 0.005$ & $0.054 \pm 0.008$ & $0.007 \pm 0.001$ & $0.030 \pm 0.011$ & $0.127 \pm 0.011$ & $82.4 \pm 4.8$ \\
\hline & & Eff. & $0.001 \pm 0.001$ & $0.004 \pm 0.002$ & $0.001 \pm 0.000$ & $0.016 \pm 0.005$ & $0.022 \pm 0.005$ & \\
\hline \multicolumn{9}{|l|}{ Plant 2} \\
\hline \multirow[t]{2}{*}{ Sep, 27th } & \multirow[t]{2}{*}{20.7} & Inf. & 0.037 & 0.064 & 0.016 & 0.032 & 0.149 & 89.9 \\
\hline & & Eff. & 0.001 & 0.001 & 0.001 & 0.012 & 0.015 & \\
\hline \multirow[t]{2}{*}{ Dec, 17th } & \multirow[t]{4}{*}{13.8} & Inf. & 0.029 & 0.071 & 0.013 & 0.023 & 0.136 & 89.7 \\
\hline & & Eff. & 0.001 & 0.002 & 0.002 & 0.009 & 0.014 & \\
\hline Average \pm S.D. & & Inf. & $0.033 \pm 0.005$ & $0.067 \pm 0.006$ & $0.014 \pm 0.002$ & $0.028 \pm 0.007$ & $0.142 \pm 0.008$ & $89.8 \pm 1.4$ \\
\hline & & Eff. & $0.001 \pm 0.000$ & $0.001 \pm 0.001$ & $0.002 \pm 0.001$ & $0.010 \pm 0.002$ & $0.014 \pm 0.001$ & \\
\hline Plant 3 & & & & & & & & \\
\hline Oct, 26th & 20 & Inf. & 0.038 & 0.067 & 0.110 & 0.132 & 0.347 & 90.8 \\
\hline & & Eff. & ND & ND & 0.001 & 0.031 & 0.032 & \\
\hline Dec, 17th & 14.8 & Inf. & 0.085 & 0.106 & 0.016 & 0.060 & 0.267 & 90.3 \\
\hline & & Eff. & ND & ND & 0.002 & 0.024 & 0.026 & \\
\hline Average \pm S.D. & & Inf. & $0.062 \pm 0.033$ & $0.086 \pm 0.027$ & $0.063 \pm 0.067$ & $0.096 \pm 0.051$ & $0.308 \pm 0.057$ & $90.6 \pm 3.5$ \\
\hline & & Eff. & ND & ND & $0.002 \pm 0.001$ & $0.028 \pm 0.005$ & $0.030 \pm 0.004$ & \\
\hline Plant 4 & & & & & & & & \\
\hline Oct, 26th & 18.7 & Inf. & 0.034 & 0.036 & 0.028 & 0.085 & 0.183 & 88.0 \\
\hline & & Eff. & ND & ND & ND & 0.022 & 0.022 & \\
\hline July, 16th ${ }^{\mathrm{a}}$ & 23.0 & Inf. & 0.030 & 0.028 & 0.034 & 0.080 & 0.172 & 89.5 \\
\hline & & Eff. & ND & ND & ND & 0.018 & 0.018 & \\
\hline Average \pm S.D. & & Inf. & $0.032 \pm 0.003$ & $0.032 \pm 0.005$ & $0.031 \pm 0.004$ & $0.083 \pm 0.004$ & $0.178 \pm 0.008$ & $88.8 \pm 1.1$ \\
\hline & & Eff. & ND & ND & ND & $0.020 \pm 0.003$ & $0.021 \pm 0.003$ & \\
\hline
\end{tabular}

a The samplings times were in 2008, while others in 2007. 


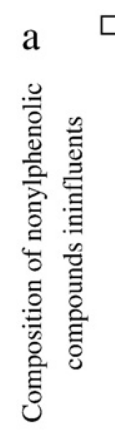

$\square \mathrm{NP}$ \NPEOs(n=1,2) $\square \mathrm{NPnEOs}(\mathrm{n}=3-15) \quad \square \mathrm{NPnECs}$

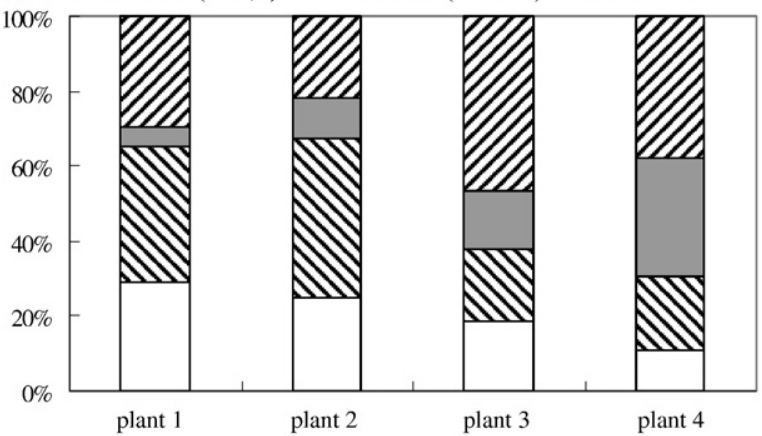

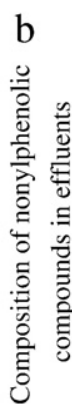

$\square \mathrm{NP} \quad \mathbf{N P n E O s}(\mathrm{n}=1,2)$ $100 \%$

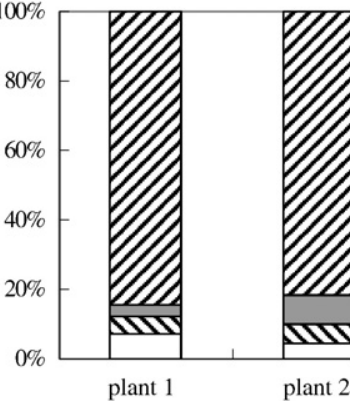

$\square \mathrm{NPnEO}(\mathrm{n}=3-15)$

$\square$ NPECs
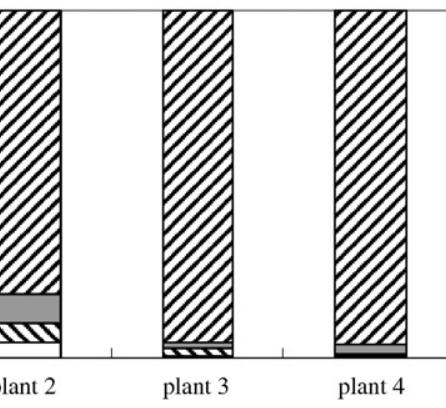

Fig. 1. Relative abundance of NPnEOs and their metabolites in sewage influents (a) and effluents (b) of the four WWTPs.

68.3-94.7\% of the totals. These results were inconsistent with those of other countries, in which the group of long-chain NPnEOs was the most abundant group in the influent (82.4\%) (Ahel et al., 1994), but were accordant with the other results obtained in China (Shao et al., 2003), which reported that NPnEOs $(n \geq 3)$ was only one third of the total nonylphenolic compounds in the influents. The difference between China and other countries might be due to the relatively longer sewers entering WWTPs in China, so a large amount of long-chain NPnEOs were already transformed into the metabolites before introduced to WWTPs, resulting in the lower contribution than other countries. Distributions of nonylphenolic compounds between aqueous phase and solid phase in the influent were different. Taking the influent in one sampling event for plant 2 for example, Fig. 2 shows the percentages that dissolved portion and adsorbed portion occupied for each oligmer of nonylphenolic compounds. It can be seen that the adsorbed portion decreased as the EO chain length increased, and NPECs occupied the smallest percentage. It is already known that the octanol-water partition coefficients $\log$ Kow values for NP, NP1EO, NP2EO and NP3EO are 4.48, 4.17, 4.21 and 4.20, respectively (Ahel and Giger, 1993), and decreases as the EO chain length increases. Therefore, this finding supported that with the EO chain length increasing, the NPnEO oligomers become more hydrophilic. In addition, the removals of nonylphenolic compounds in the dry weather were equally comparable across the four WWTPs, ranging from $75.7 \%$ to $90.8 \%$, reflecting that good elimination of nonylphenolic compounds in wastewater could be achieved during existing wastewater treatment processes (Table 3 ).

Regarding the effluents of WWTPs, NPECs were as expected the most abundant group (Fig. 1b), indicating NPECs were the main metabolites of NPnEOs during biological degradation processes (Ahel et al., 1994; Loyo-Rosales et al., 2007).

\subsection{Impact of weather on the occurrence and elimination of NPnEOs and their metabolites}

For plant 2 and plant 3, sampling events occurred in September, October and December 2007, in order to study the impact of ambient temperature on the occurrence and elimination of NPnEOs and their metabolites in the WWTPs. As mentioned by a report (Loyo-Rosales et al., 2007), samples were considered as "the summer" if water temperature was above $20^{\circ} \mathrm{C}$ and as "the winter"if it was below $15^{\circ} \mathrm{C}$. The total concentrations of nonylphenolic compounds in the influents and removal of NPnEOs $(n \geq 3)$ in the summer and the winter for plant 2 and plant 3 were illustrated in Fig. 3. These results showed that the influent concentrations of both WWTPs were a little higher in the summer than in the winter. This phenomenon was probably due to more washing events and larger NPnEOs surfactants consumption in the summer. Correspondingly, there was a similar seasonal effect on the removal of NPnEOs $(n \geq 3)$, in which higher NPnEOs $(n \geq 3)$ removals occurred in the summer for the both plants. The other three groups of nonylphenolic compounds including NP, NPnEOs $(n=1,2)$ and NPECs were not only biodegraded but also produced during wastewater treatment process, whereas NPnEOs $(n \geq 3)$ were only biodegraded, so the removal of NPnEOs $(n \geq 3)$ could reflect the extent of biodegradation. Obviously, high ambient temperature is helpful for higher biodegradation of the long-chain NPnEOs in both plants.

In previous studies, wastewater samples were generally obtained in the dry weather, and few studies have addressed the behaviour of nonylphenolic compounds in WWTPs in the rain weather. On July 11th and 14th in 2008, when Beijing was during the rainy season and the two days before which were continuously rainy, sampling events were conducted from plant 1 , in order to discuss whether the rain weather had any effect on the influent concentrations and removal of nonylphenolic compounds. As shown in Fig. 4, June 14th, July 8th, July 24th, and September 11th in 2007 and July 18th in 2008 were sunny during the dry weather, while July 11 th and 14th in 2008 were rainy. It can be seen that the total concentration of nonylphenolic compounds in the influents were remarkably lower in the rainy days approximately $60 \%$ of those in the dry weather. The difference was also observed in terms of COD in the influents. Compared to the dry weather, COD of the influents decreased $10-29 \%$ in the rain weather. It

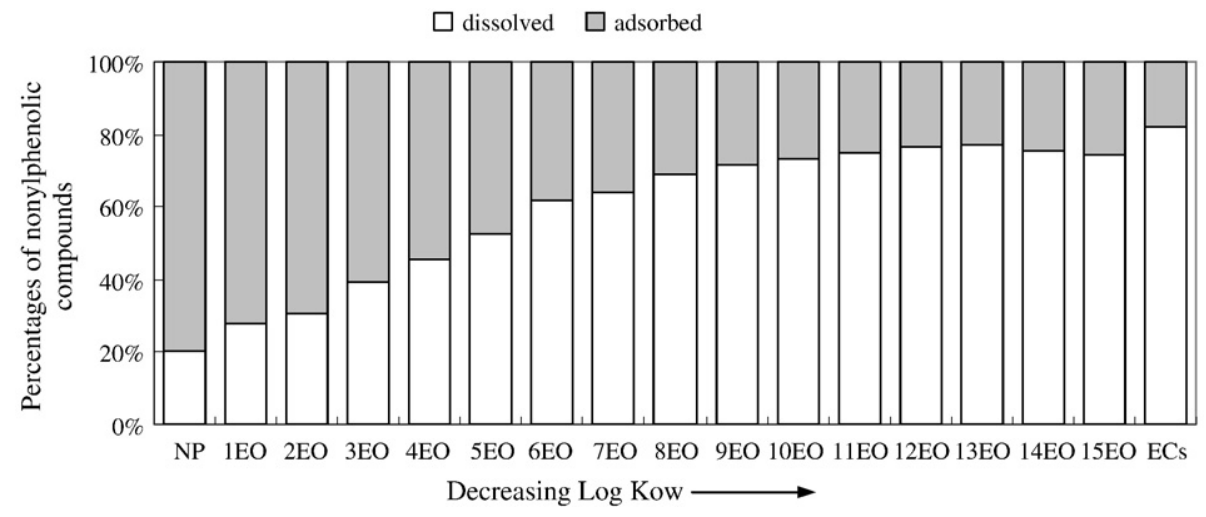

Fig. 2. Distributions of nonylphenolic compounds in aqueous and solid phase of the influent in plant 2. 


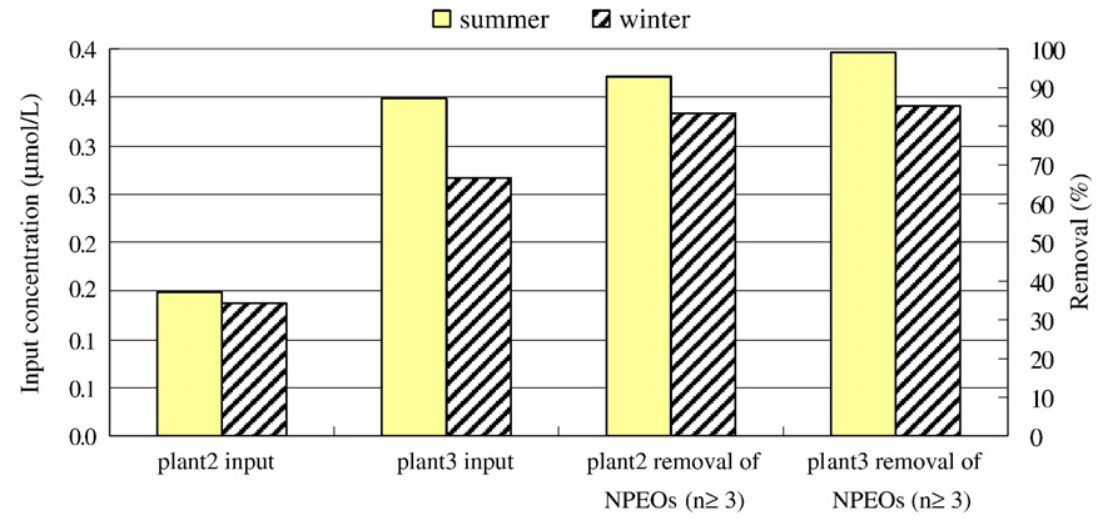

Fig. 3. The total influent concentrations of NP-c and removals of long-chain NPnEOs in the summer and the winter for plant 2 and plant 3.

was rainy everyday from July 9 th to July 14 th, and the input flow of plant 1 was about $500 \times 10^{3}-600 \times 10^{3} \mathrm{~m}^{3} /$ day during those days (data supplied by plant 1 ), which was about one third time larger than that in the dry weather, due to that the sewerage system that served plant 1 was not closed. Therefore, the dilution caused by the rainwater led to the lower levels of COD and nonylphenolic compounds in the influents. However, no remarkable differences were found in removal rates of both COD and nonylphenolic compounds between the dry weather and the rain weather (data not shown), indicating that rainfall had little impact on the removal efficiencies of nonylphenolic compounds and COD in the WWTP. This may be a compositive function caused by rainwater dilution, microorganisms and long hydraulic residence time (HRT) of the wastewater treatment system.

\subsection{Output pathways of NPnEOs and their metabolites in WWTPS}

In previous studies, the elimination of NPnEOs and their metabolites during wastewater treatment process was generally expressed by the ratios of nonylphenolic compounds concentrations in the effluent to those in the influent. The eliminated nonylphenolic compounds were perhaps not completely degraded, leaving a considerable amount being absorbed into sludge flocs due to their affinity to solids (LoyoRosales et al., 2007; Stasinakis et al., 2008; Pothitou and Voutsa, 2008). In this study, not only concentrations of nonylphenolic compounds in wastewater samples, but also those in sludge samples were determined, then mass balance of nonylphenolic compounds in the whole wastewater treatment processes can be obtained taking related WWTPs operational parameters into consideration (Fig. 5), and output pathways of NPnEOs and their metabolites in WWTPs can be summarized. Flow chart for a representative WWTP is given in Fig. 5, and various flow rates were introduced respectively for the four plants, in order to obtain mass balances of the total nonylphenolic compounds in each of the four plants. The concentrations in wastewater and excess sludge samples introduced to get mass balances were the average values of the several investigation results in dry weather.

The nonylphenolic compounds removal in the grit chamber was first considered. Taking plant 1 as an example, the concentration of NP adsorbed to grits was $0.029 \mathrm{mmol} / \mathrm{kg}$. Taking sand discharged amount into account, NP release via sand discharging could be calculated, being $0.3 \mathrm{mmol}$ per day, accounting for $0.004 \%$ of NP input to the WWTP. The portion was too small to be considered, and other NPnEOs metabolites eliminations via sand discharge were also ignored because they were less likely to be adsorbed to grits compared to NP. Therefore, it is considered that the grit chamber had no influence on nonylphenolic compounds removal.

As can be seen from the mass balance of nonylphenolic compounds in WWTPs, output pathways of nonylphenolic compounds from WWTPs were summarized to be biodegradation, adsorption onto sludge and release via effluents. Comparing these results to other investigations, at least $60-65 \%$ of nonylphenolic compounds entering the Switzerland WWTPs (Ahel et al., 1994) were discharged into the environment via effluents and adsorption onto sludge, and $30-89 \%$ of the incoming nonylphenolic compounds in American WWTPs (LoyoRosales et al., 2007) were released by effluents and sludge, leaving 11$70 \%$ for microbial transformation. On the contrast, the four surveyed WWTPs of Beijing in this study released a smaller amount, 21.8-47.6\% of the input nonylphenolic compounds into environment, indicating more nonylphenolic compounds were missing during biodegradation. Higher elimination efficiencies during biological treatment in these four WWTPs may be the result of low concentrations of nonylphenolic compounds in the influents, but needs further investigations.

For plant 1 and plant 4 , the ratios of biodegradation amount to adsorption amount were 6.9 and 8.5, respectively, while for plant 2 and plant 3 , the ratios were 1.3 and 3.0 , respectively. It is important to note

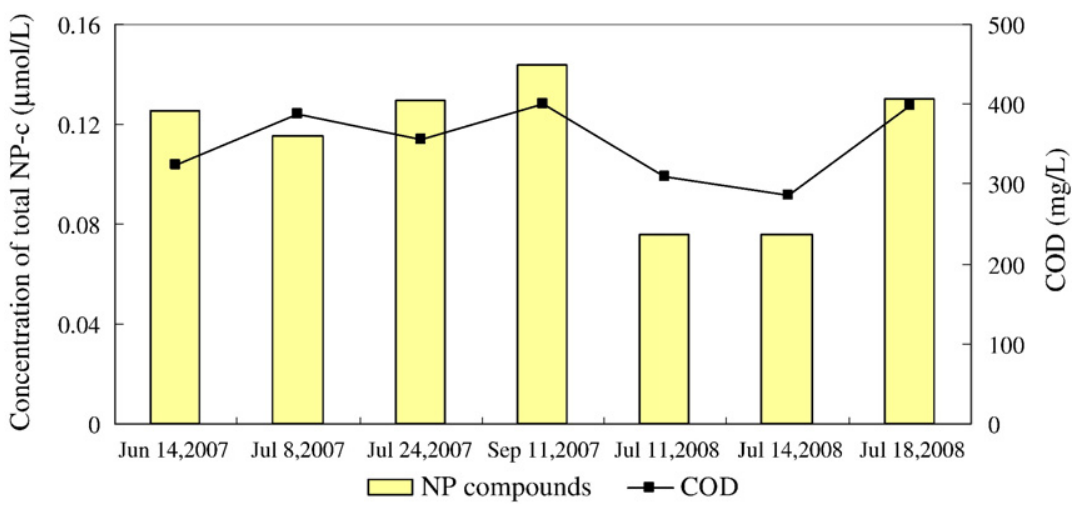

Fig. 4. COD and total concentrations of NP-c in influents of plant 1 in dry and rain weather. 

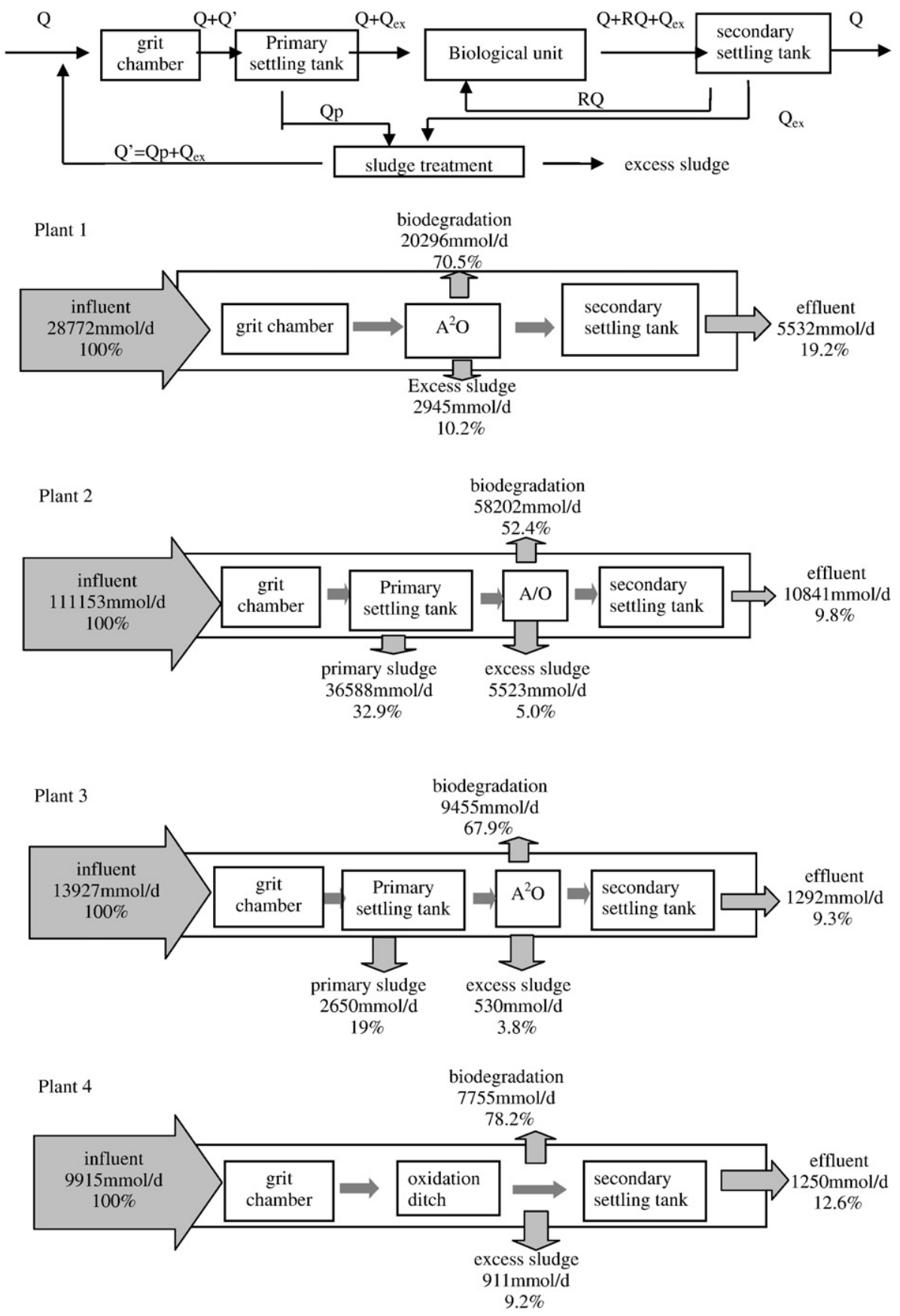

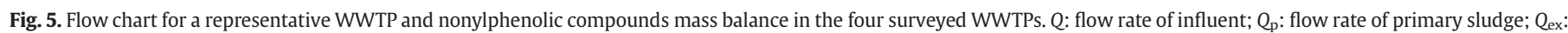
flow rate of excess activated sludge; $R$ : reflux ratio; $Q^{\prime}$ : supernatant stream of sludge area, amounting to $Q_{\mathrm{p}}+Q_{\mathrm{ex}}$.

that plant 2 and plant 3 possessed primary settling tanks. It is hypothesized that a great deal of nonylphenolic compounds were adsorbed onto sludge flocs in primary settling tanks before entering the biological treatment units, resulting in a larger amount via the adsorption pathway, thus leading to lower ratios of the amount biodegraded to that adsorbed. On the other hand, the total concentration of nonylphenolic compounds in primary sludge was $0.915 \mathrm{mmol} / \mathrm{kg}$, exceeding the concentration in excess sludge $(0.066 \mathrm{mmol} / \mathrm{kg})$ greatly, which confirmed that primary sludge had significant adsorption to nonylphenolic compounds due to larger amount of input nonylphenolic compounds in the primary settling tank than that in the second settling tank. From the above it can be concluded that the primary settling tanks played an important role in the adsorption output pathway for nonylphenolic compounds during wastewater treatment process.

\subsection{Output pathways of each group of NPnEOs metabolites in WWTPS}

Except the sum of nonylphenolic compounds, the fates of each group of NPnEOs and their metabolites in the four WWTPs were shown in Fig. 6. As far as NP and NPnEOs $(n=1,2)$ were concerned, biodegradation pathways accounted for $60 \pm 30 \%$ and $59 \pm 26 \%$ of the mass input, respectively, followed by the contribution accumulated in the excess sludge ( $40 \pm 25 \%$ and $41 \pm 27 \%$, respectively), whereas a minor part ( $1.8 \pm 1.2 \%$ and $1.5 \pm 1.0 \%$, respectively) was discharged via effluents. NP and NPnEOs $(n=1,2)$ were inclined to congregate onto sludge flocs in contrast to other metabolites because of their higher hydrophobicities. It is noteworthy that in plants 2 and 3, the amounts of NP and NPnEOs $(n=1,2)$ in the sludge were evidently larger than those in plants 1 and 4, probably due to the presence of the primary 


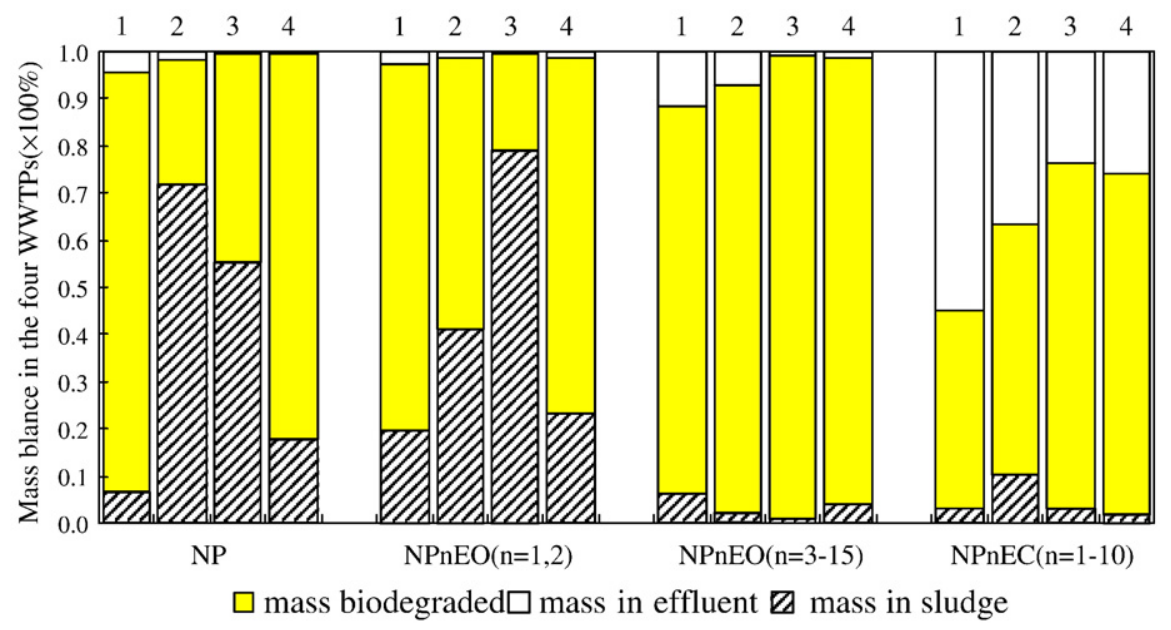

Fig. 6. Mass balance of each group of nonylphenolic compounds in the four WWTPs.

settling tanks in plants 2 and 3 that allowed more compounds attached to sludge before being biodegraded. The amounts of these compounds in the sludge of the four WWTPs were shown in Table 4. Concentrations of three excess sludge samples were detected in each WWTP during one sampling event, and the listed data in Table 4 were the ranges of the results in the four WWTPs. Remarkable elevated concentrations of NP and NPnEOs $(n=1,2)$ were identified in sludge after anaerobically stabilized, as a result of transformation products of NPnEOs $(n=3-15)$ during sludge digestion. It was proved that NP and NPnEOs $(n=1,2)$ were weakly estrogenic, with potencies between about $1 \times 10^{-4}$ to $1 \times 10^{-6}$ the activity of $17 \beta$-oestradiol (Jobling and Sumpter, 1993). Therefore, Although contamination of nonylphenol in sewage sludge in China was less serious than other countries (La Guarkia et al., 2001; Pryor et al., 2002; Aparicio et al., 2007), it has provoked more and more attention because above $60 \%$ of the total sewage sludge was recycled to agricultural land (Soares et al., 2008).

Fig. 6 presents that NPnEOs $(n \geq 3)$ were mainly biodegraded during the wastewater treatment process, being mineralized or transformed to their metabolites, while a considerable portion of NPECs was emitted via effluents, resulting in the most part of the total nonylphenol compounds in effluents (Fig. 1b). It has been proposed that NPECs, especially NPnECs $(n=1,2)$ had the similar estrogenic activities to short-chain NPEOs (Jobling and Sumpter, 1993), so further work is needed in terms of evaluating the possible risks of effluents and developing related contamination control technologies in WWTPs.

\section{Conclusions}

The occurrence and fate of a comprehensive group of nonylphenol polyethoxylates and their metabolites were investigated in four Beijing WWTPs. Conclusions are made as follows:

Influents concentrations of the total nonylphenolic compounds ranged from 0.115 to $0.347 \mu \mathrm{mol} / \mathrm{L}$, and the removals of these compounds in wastewater were as high as $75.7 \%$ to $90.8 \%$, reflecting good elimination effects of existing wastewater treatment processes for nonylphenolic compounds. Higher temperature may accelerate

Table 4

Concentrations of NPnEOs $(n=0-2)$ in sludge.

\begin{tabular}{lccc}
\hline Sample source & \multicolumn{3}{l}{ Concentrations $(\mathrm{mg} / \mathrm{kg})$} \\
\cline { 2 - 4 } & $\mathrm{NP}$ & $\mathrm{NP} 1 \mathrm{EO}$ & \multicolumn{1}{c}{ NP2EO } \\
\hline Excess sludge & $3.1-22.3$ & $3.4-38.7$ & $5.5-32.8$ \\
Sludge anaerobically stabilized & $149.6-167.2$ & $27.6-30.1$ & $9.5-11.0$ \\
\hline
\end{tabular}

microbial transform of long-chain NPnEOs. The rain weather decreased nonylphenolic compounds input to WWTPs as well as COD by dilution, but had no remarkable impact on the removal efficiences compared to those in the dry weather.

NPnEOs and their metabolites entering WWTPs were output mainly through three pathways: biodegradation, adsorption onto sludge and release via effluents. $21.8-47.6 \%$ of the input amount was emitted into environment via effluents and sludge, leaving a considerable portion of nonylphenolic compounds available for microbial transformation. The grit chamber had nothing to do with elimination of nonylphenolic compounds, while the primary setting tank played an important role on the adsorption pathway.

NP and NPnEOs $(n=1,2)$ tended to adsorb onto sludge flocs because of their high hydrophobic properties, on the other hand, NPECs occupied most of nonylphenolic compounds in effluents due to their relative hydrophilic properties, both of which could raise environmental risk. The future must lie in the elimination of the residual nonylphenolic compounds in wastewater and sludge, and advanced oxidation process could perhaps be added followed by biological wastewater treatment process, which needs further discussion.

\section{Acknowledgement}

This work was funded by the National Natural Science Foundation of China (No. 50538090).

\section{References}

Ahel M, Giger W. Partitioning of alkylphenols and alkylphenol polyethoxylates between water and organic solvents. Chemosphere 1993;26:1471-8.

Ahel M, Giger W, Koch M. Behaviour of alkylphenol polyethoxylate surfactants in the aquatic environment-I. Occurrence and transformation in sewage treatment. Water Res 1994;28:1131-42.

Aparicio I, Santos JL, Alonso E. Simultaneous sonication-assisted extraction, and determination by gas chromatography-mass spectrometry, of di-(2-ethylhexyl) phthalate, nonylphenol, nonylphenol ethoxylates and polychlorinated biphenyls in sludge from wastewater treatment plants. Anal Chim Acta 2007;584:455-61.

Bruno F, Curini R, Corcia AD, Fochi I, Nazzari M, Samperi R. Determination of surfactants and some of their metabolites in untreated and anaerobically digested sewage sludge by subcritical water extraction followed by liquid chromatography-mass spectrometry. Environ Sci Technol 2002;36:4156-61.

Corcia AD, Cavallo R, Crescenzi C, Nazzari M. Occurrence and abundance of dicarboxylated metabolites of nonylphenol polyethoxylate surfactants in treated sewages. Environ Sci Technol 2000;34:3914-9.

Fujita Y, Reinhard M. Identification of metabolites from the biological transformation of the nonionic surfactant residue octylphenoxyacetic acid and its brominated analog. Environ Sci Technol 1997;31:1518-24.

Fujita M, Ike M, Mori K, Kaku H, Sakaguchi Y, Asano M, et al. Behaviour of nonyphenol ethoxylates in sewage treatment plants in Japan-biotransformation and ecotoxicity. Water Sci Technol 2000;42:23-30. 
Hao RX. Fate of nonylphenol during sewage treatment process. China Wat Wastew 2007;23:105-8 (in Chinese).

Harries JE, Sheahan D, Osborne JA, Mathiessen P, Neall P, Routledge EJ, et al. A survey of estrogenic activity in United Kingdom inland waters. Environ Toxicol Chem 1996;15:1993-2002.

Hou SG, Sun HW. Occurrence of NPnEO in four sewage treatment plants in north China. Stud Environ Sci 2006;19(3):61-6 (Chinese).

Jobling S, Sumpter JP. Detergent components in sewage effluent are weakly oestrogenic to fish: an in vitro study using rainbow trout (Oncorhynchus mykiss) hepatocytes. Aquat Toxicol 1993;27:361-72.

Korner W, Bolz U, Sumuth W, Hiller G, Schuller W, Hanf V, et al. Input/output balance of estrogenic active compounds in a major municipal sewage plant in Germany. Chemosphere 2000;40:1131-42.

La Guarkia MJ, Hale RC, Harvey EP, Mainor TM. Alkylphenol ethoxylate degradation products in land-applied sewage sludge (biosolids). Environ Sci Technol 2001;35:4798-804.

Loyo-Rosales JE, Rice CP, Torrents A. Fate of octyl- and nonylphenol ethoxylates and some carboxylated derivatives in three American wastewater treatment plants. Environ Sci Technol 2007;41:6815-21.

Ma XJ, Shao B, Hu JY, Yang M. Transformation of nonylphenol polyethoxylates during wastewater treatment process. Environ Sci 2002;23:80-3 (in Chinese).

Planas C, Guadayol JM, Droguet M, Escalas A, Rivera J, Caixach J. Degradation of polyethoxylated nonylphenols in a sewage treatment plant. Quantitative analysis by isotopic dilution-HRGC/MS. Water Res 2002;36:982-8.
Pothitou P, Voutsa D. Endocrine disrupting compounds in municipal and industrial wastewater treatment plants in Northern Greece. Chemosphere 2008;73:1716-23.

Pryor SW, Hay AG, Walker LP. Nonylphenol in anaerobically digested sewage sludge from New York state. Environ Sci Technol 2002;36:3678-82.

Scrimshaw, M.D. Lester, J.N., Fate and behaviour of endocrine disrupters in sludge treatment and disposal. In: Birkett, J.W., Lester, J.N. Endocrine disrupters in wastewater and sludge treatment processes. Lewis publishers, CRC press LCL and IWA publishing, London, 2003, pp. 145-76.

Shao B, Hu JY, Yang M. Nonylphenol ethoxylates and their biodegradation intermediates in water and sludge of a sewage treatment plant. Bull Environ Contam Toxicol 2003;70:517-32.

Soares A, Guieysse B, Jefferson B, Cartmell E, Lester JN. Nonylphenol in the environment : a critical review on occurrence, fate, toxicity and treatment in wastewaters. Environ Int 2008;34:1033-49.

Stasinakis AS, Gatidou G, Mamais D, Thomaidis NS, Lekkas TD. Occurrence and fate of endocrine disrupters in Greek sewage treatment plants. Water Res 2008;42:1796-804.

Zhang J, Zhang Y, Yang M, Jin F, Chen MX. Simultaneous determination of nonylphenol ethoxylates and their biotransformation products by liquid chromatography/ electrospray ionization tandem mass spectrometry. J Instrum Anal 2007;26:178-82 (in Chinese). 